\title{
CARMEN EM PERSPECTIVA DIALÓGICA: REVERBERAÇÕES INQUIETAS DE UM PROCESSO DE CONSTRUÇÃO DRAMATÚRGICO-PERFORMATIVA NO CONTEXTO UNIVERSITÁRIO*
}

Jean Carlos GONÇALVES ${ }^{* *}$

Michelle BocCHI GONÇALVES ${ }^{* * *}$

Resumo:

O objetivo deste texto é refletir sobre o processo de construção dramatúrgica do espetáculo Carmen, realizado no contexto da Graduação em Produção Cênica da Universidade Federal do Paraná. As relações com a teoria se estabelecem a partir da perspectiva dialógica que tem na produção intelectual de Bakhtin e o Círculo, sua principal ancoragem. Os resultados apontam para aproximações entre a esfera educacional, o discurso cênico e a consequente mobilização da noção bakhtiniana de relações dialógicas, o que sugere diferentes possibilidades para se pensar a construção dramatúrgica em uma concepção alicerçada no corpo como enunciador e produtor de sentidos.

PALAVRas-ChaVE: Construção dramatúrgico-performativa, corpo, universidade, Bakhtin e o Círculo.

\section{ApresentaÇão}

Este texto tem como objetivo central refletir sobre o processo de construção dramatúrgica do espetáculo Carmen, realizado no contexto da Graduação em Produção Cênica da Universidade Federal do Paraná

* O presente trabalho foi realizado com o apoio do CNPq - Conselho Nacional de Desenvolvimento Científico e Tecnológico.

** Professor da Universidade Federal do Paraná (UFPR), Curitiba, Paraná, Brasil. E-mail: jeancarllos@ufpr.br

*** Professora da Universidade Federal do Paraná (UFPR), Curitiba, Paraná, Brasil. E-mail: michellebocchi@gmail.com 
em 2015/16, mais especificamente no âmbito das disciplinas Laboratório Experimental de Dramaturgias do Ator, Laboratório Experimental de Linguagens Cênicas e Laboratório de Performance. O olhar para o processo se dá a partir da teoria dialógica do discurso, ou seja, ancorase na perspectiva de linguagem dos estudos de Bakhtin e o Círculo.

O espetáculo Carmen surgiu a partir da necessidade de um grupo de alunos-atores de discutir temas relacionados ao corpo e sua(s) liberdade(s) e limite(s). A pergunta: "o que o corpo não pode?" foi o disparador poético para a construção de partituras e matrizes corporais que foram surgindo no diálogo com materialidades discursivoenunciativas abarcadas por diferentes tempos e espaços.

A urgência da discussão aqui proposta está na conexão que se apresenta entre os estudos da linguagem, da educação e do teatro e, ainda, na centralidade da construção dramatúrgico-performativa como um processo híbrido e múltiplo, compreendido neste trabalho a partir de uma visão de inacabamento e provisoriedade constitutivos da obra em questão. $O$ resultado do trabalho prático em sala de aula não se apresenta como um espetáculo pronto, já que o caráter experimental é intrínseco às ementas das disciplinas. Embora o espetáculo já tenha se aventurado em apresentações públicas em Curitiba, região metropolitana e litoral do estado do Paraná, o grupo compreende a atualidade temática abordada e acaba inserindo no processo situações vivenciadas no dia a dia e memórias recentes que tenham relação com a abordagem proposta.

O texto se apresenta em duas seções. A primeira é dedicada à análise dialógica do discurso, para que o leitor possa compreender o mirante teórico que constitui o olhar (bakhtiniano) para o processo. A segunda discute a construção dramatúrgico-performativa de Carmen, apontando, ao mesmo tempo, detalhamentos metodológicos do processo e sua relação com a teoria de análise.

A inquietude, anunciada no título do trabalho, permeia todo o texto em virtude da apaixonada reflexão de um professor-diretor e uma professora-performer sobre um processo que os marca. Mais do que o olhar de pesquisadores que tenham, por um tempo, se distanciado do seu objeto e depois tornam a vê-lo por outra perspectiva, esse texto contém o sangue que ferve nas veias quentes do treinamento físico com 
os alunos-atores, a alma-artista que se move na luta por desejos de dizer e ser dos sujeitos com os quais interage e o corpo-professor [envolvido e emocionado] que pulsa e vibra com cada possibilidade estética recorrente dos processos e experiências educacionais em diferentes contextos.

\section{TeORIA DiAlÓGICA E O FENÔMENO ARTíSTICO}

A análise/teoria dialógica do discurso constitui-se, hoje, como o conjunto de formulações teóricas advindas dos estudos de um grupo de intelectuais russos, que se reunia no início do século passado para discutir uma abrangência de temas que iam das artes à literatura e linguagem, denominado de Bakhtin e o Círculo. O grupo, que tinha na figura de Mikhail Bakhtin (1895-1975) sua centralidade, contava com a participação de importantes nomes como Matvei Isaevich Kagan (1889-1937); Borís Zubákin (1894-1938); Pavel Nikolaevich Medvedev (1891-1938); Liev Vasilievich Pumpianskii (1891-1940); Ivan Ivanovich Sollertinskii (1902-1944); Valentin Volóchinov (18951936), Maria Iudina (1899-1970) (BRAIT, 2012; GRILLO, 2012).

Bakhtin (2010b) concebe a constituição do sujeito a partir da interação com o outro. Na situação de enunciação o sujeito provoca no seu interlocutor uma atitude responsiva, permeada pelo ambiente no qual a comunicação acontece. É em práticas discursivas, então, que os sujeitos mostram-se, percebem suas diferenças, atribuem sentidos ao discurso alheio e vice-versa. A perspectiva de Bakhtin e o Círculo, conhecida, também, como perspectiva dialógica tem na interação entre sujeitos seu cerne de discussão.

Os sujeitos da enunciação estão inseridos em um ambiente de inter-relação social dentro de um determinado contexto, e é esse contexto que vai definir a situação enunciativa. No caso desta pesquisa, a interlocução textual se dá em uma esfera universitária que, por sua vez, é, também, artística. É a partir do jogo de vozes que compõem os discursos/dizeres/dramaturgias dos alunos-atores, que é possível investigar a produção de sentidos do processo de construção do espetáculo em questão. 
Não pode haver enunciado isolado. Ele sempre pressupõe enunciados que o antecedem e o sucedem. Nenhum enunciado pode ser o primeiro ou o último. Ele é apenas o elo na cadeia e fora dessa cadeia não pode ser estudado. Entre os enunciados existem relações que não podem ser definidas em categorias nem mecânicas nem linguísticas. Eles não têm analogias consigo (BAKHTIN, 2003, p. 371).

Para Bakhtin (2010b), um ponto de vista histórico, social e cultural, incluindo a comunicação entre os sujeitos produtores do discurso é crucial nas discussões sobre linguagem. É a partir de uma determinada esfera de produção enunciativa que os sujeitos interagem, criam novas oportunidades de diálogo, e, por consequência, se constituem. Para o autor, a enunciação é um componente da realidade que possui uma estrutura organizada sócio-ideologicamente, que tem sua forma e estilo determinados.

Os sujeitos, socialmente organizados, interagem através de seus dizeres e produzem sentidos por meio deles. No caso do teatro, no qual está em jogo, para além das relações reais entre sujeitos, relações de produção artística, a teoria bakhtiniana se aplica mais do que coerentemente, principalmente por sua negação dos lugares e identidades fixas. Em Brait (2005), percebemos que os sujeitos da enunciação acabam deixando marcas do lugar histórico e social de onde enunciam, e aí, dão pistas ao seu destinatário, e este vai produzindo também os sentidos que serão responsáveis pela construção de outros enunciados que, no contexto universitário, dialogam com sua formação, e também com a esfera na qual atuam em uma dupla função (a de aluno e a de ator).

Uma das reflexões que interessam às discussões propostas nesse texto é a noção de campo/esfera da comunicação enunciativa, da qual fala Bakhtin. Primeiramente é preciso pensar que um enunciado absolutamente neutro é impossível. O enunciado sempre está em diálogo com seus elos precedentes e posteriores, e é condicionado a diferentes identidades temáticas e por seu pertencimento a determinados campos da atividade humana (GRILLO, 2008). É aqui que se torna relevante pensar a construção dramatúrgica como uma autoria absolutamente comprometida (com histórias, trajetórias, vivências e com o corpo do ator). 
Na perspectiva dialógica, é ao enunciar que o sujeito responde ativamente a enunciados precedentes e também considera a antecipação da posição responsiva do seu interlocutor. A interlocução, no processo artístico, se dá com diferentes materialidades, como anunciado anteriormente. Logo, o meu outro não é somente um outro físico (igual a mim), mas um outro que pode reorganizar-me enunciativodiscursivamente. Aí mora a base da teoria bakhtiniana: sua compreensão consiste em olhar para a palavra do outro como uma palavra não separada do contexto em que é produzida, e esse outro sempre será, para mim, a minha possibilidade de autoria (seja ela uma autoria do campo do real ou do campo artístico).

$\mathrm{O}$ viés bakhtiniano defende uma compreensão que é "ativa, dialógica, que é busca de sentido, que contém a possibilidade da contrapalavra ou da réplica, e que é, portanto, interpretação responsiva" (KRAMER, 2007, p. 183). Nessa perspectiva, não há um olhar crítico sobre o objeto, como no caso de outras interpretações de dados e, sim, uma busca por compreender modos de ser, de viver, de se relacionar, de criar.

Uma das questões que merecem destaque é o fato de que Bakhtin foi o primeiro pensador contemporâneo a falar da linguagem sem dissociá-la da própria materialidade da vida social, e esse modo de pensar a condição humana em seu mais variado senso de globalidade permite uma pesquisa dialógica, através da qual seja possível "ouvir e escutar amorosamente a palavra do outro" (FARACO, 2007, p. 99). É assim, bakhtinianamente falando, que o processo Carmen foi construído, considerando que o universo das trocas se constitui num olhar para o outro, num debruçar-se sobre o pensamento do outro, seus enunciados, seu corpo, seus valores, até que o resultado dessa mistura possa se apresentar com uma finalidade artística que comunique/expresse os desejos de dizer de todo o grupo, sem anular as individualidades de cada participante da criação artística.

Em uma situação de enunciação um sujeito fala sobre si e sobre o outro, e ao seu enunciado são atribuídos sentidos que apontam para o lugar de onde ele fala, e para as circunstâncias culturais, históricas e sociais nas quais a interação acontece. Segundo Lopes (1998), os interlocutores vão construindo sentidos ao se envolverem e ao envolverem os outros 
na enunciação. É por esse processo de constituição do sentido, no qual a presença do interlocutor é indispensável, que as pessoas se tornam conscientes de quem são e constroem suas identidades sociais a partir da linguagem (AMORIM, 2004). Nessa perspectiva, é possível compreender a criação teatral como meio de reflexão sobre determinado objeto que, por consequência, acaba sempre sendo o próprio homem, sempre o(s) sujeito(s) das interações.

Construir dramaturgias, organizar textualidades com fins comunicativos, criar teatralidades são, desse modo, atividades essencialmente interativas. Para Bakhtin (2010b), cada sujeito, a partir do enunciado do outro, constrói sua autoimagem e se posiciona socialmente, exercendo diferentes posições e estruturando sua personalidade individual. É por meio da linguagem, realizada em determinado território social, que a enunciação está situada como produto de interação e as relações são estabelecidas. Por meio de uma cadeia de enunciados que vão sendo produzidos, os sujeitos atribuem sentidos e vão sofrendo alternâncias ocasionadas pelas vozes sociais que permeiam a esfera na qual a situação de enunciação está acontecendo.

O interesse deste texto recai sobre práticas in situ, ou seja, é para o processo de construção dramatúrgica que o olhar de análise é direcionado. Para tanto, a próxima seção se dedica a uma descrição detalhada das motivações e do percurso de Carmen, de forma que seja possível ao leitor, mesmo sem ter acompanhado de perto as aulasensaios, se aproximar do universo temático dessa construção por alguns vestígios possíveis. A opção, nesta próxima seção, foi por uma narrativa que possa relatar e analisar o vivido sem a necessidade de trazer para o texto as materialidades levadas para a sala de aula-ensaio. Também não compõem o texto fotografias do processo e nem mesmo do espetáculo diante do público, escolha que se deve à mesma opção pelo relato escrito.

\section{CARMEN: DiÁlogos SOBRe o PROCESSO}

O espetáculo Carmen, como anunciado no início desse texto, é um processo de construção dramatúrgico-performativa desenvolvido no âmbito das disciplinas optativas Laboratório Experimental de Dramaturgias do Ator, Laboratório Experimental de Linguagens 
Cênicas, Laboratório de Performance e Teoria da Performance, que ocorreram no primeiro e segundo semestres de 2015 e primeiro semestre e segundo semestres de 2016, respectivamente, no curso de graduação em Produção Cênica, da Universidade Federal do Paraná, em Curitiba. A partir de uma proposta que busca trabalhar com experiências teatrais fundamentadas na relação entre corpo, dramaturgia e performance, o processo Carmen se constitui de diferentes momentos, espaços, provocações, indutores de jogo e organizações cênicas.

Um primeiro fato a ser ressaltado é o de que os alunosatores integram uma graduação na área de produção cênica e não de interpretação teatral. Como as disciplinas nas quais o espetáculo começou a ser construído são optativas, somente alunos interessados em atuação/interpretação se matricularam. Isso confere às disciplinas um caráter diferenciado e privilegiado para a criação cênica, já que o motor das experiências vividas é o desejo de cada um de experimentar um processo de criação cênica.

Schino (2012) defende a noção de laboratório em sua aproximação com o termo russo studinnost, em uma referência direta ao estúdio como lugar de aprendizado. Os estúdios cênicos se caracterizaram como estopim de diversas estéticas e possibilidades, advindas de pesquisa pura e interessada nos processos orgânicos de criação e não na montagem de espetáculos. É nessa perspectiva que os integrantes de Carmen apoiam seu mirante investigativo. Sem a pretensão de criar resultados, o projeto consiste muito mais em possibilitar aos alunosatores um olhar para e sobre seus corpos-autores do que em transformar esses corpos em cena apresentável. Os encontros/ensaios se constituem, desse modo, como um lugar de cruzamentos teórico-práticos que privilegiam o autoenvolvimento nas situações artístico-pedagógicas coabitadas por eles enquanto se dedicam e se doam ao processo.

Para além do interesse pela montagem de um espetáculo, o olhar para o que estes alunos-atores querem dizer da/na relação com seus corpos motiva diferentes arranjos e estados performáticos, traduzidos por entrelaces de partituras corporais produtoras de sentido enquanto signos estético-artísticos. A noção de treinamento também interessa ao grupo e ao processo, já que é pela perspectiva de um training físico e mental que se torna possível o desenvolvimento de novos comportamentos, 
"novos modelos para se mover, agir, escutar, reagir que não devem ser simplesmente repetidos e copiados, mas que vão atingir o artista em seu ser mais íntimo" (PICON-VALLLIN, 2008, p. 69).

Ancorado no treinamento físico como mote das ações cênicas, o grupo de alunos-atores foi, inicialmente, convidado a pensar a sua relação com o corpo por meio da pergunta: "o que o corpo não pode?". A resposta à questão precisava ser via corpo, ou seja, como o corpo responde cenicamente a uma inquietação sobre si mesmo? Pensando bakhtinianamente é possível afirmar que o espetáculo só chegou nos lugares e temas atuais porque seus integrantes aceitaram a proposta de responder físico-emocionalmente a uma questão que lhes foi colocada como ponto de partida. Caso um dos quinze integrantes tivesse se recusado a respondê-la, Carmen poderia, simplesmente, não ter ganhado status de acontecimento performático ${ }^{1}$. Nesse espaço de criação, a busca dos alunos-atores e do professor-diretor tem sido por uma invasão na capacidade interpretativa do corpo como perseguição atenta à conexão com a percepção e imaginação artísticas (AZEVEDO, 2012).

Desde as primeiras aulas, e é bom que se ressalte que o processo aconteceu em um ambiente educacional/universitário e não em um ambiente profissional, os alunos-atores começaram a ter contato, para dar conta da sua questão norteadora, com diferentes materialidades externas, que contribuíram para a construção individual e coletiva do trabalho.

$\mathrm{Na}$ aula que inaugurou o processo, os alunos foram convidados a contemplar imagens bidimensionais, aleatoriamente selecionadas do banco de imagens do Google, ao se realizar uma busca com a palavra corpo. As imagens foram impressas em preto e branco e dispostas no chão da sala de aula/ensaio. Cada aluno-ator poderia se aproximar da imagem que mais lhe tocava. As imagens, escolhidas pelo professordiretor, mostravam corpos em estado de angústia, privados de suas liberdades, com amarras de caráter físico e moral, o que levou o grupo a uma visão sobre corpo bastante relacionada a insatisfações e frustrações.

Partindo da experiência com as imagens, foram realizados diversos jogos cênicos voltados para a interação entre os sujeitos e seus corpos, a partir dos quais foi possível depreender sentidos de corpo voltados às dificuldades de abraçar, tocar, acariciar e violentar o outro, ou seja, sempre que um corpo precisa estar em contato físico com outro corpo o 
resultado é um certo desconforto. Esse desconforto começava a aparecer reconfigurado em imagens corporais estáticas e dinâmicas, por meio das quais cada participante do processo era levado a criar uma partitura corporal. Nas aulas/ensaios seguintes foram realizados trabalhos de bricolagem pelos quais foi possível criar pequenas cenas de grupo.

Em meio aos jogos realizados, o grupo desenvolveu uma disposição corporal em dinamicidade que todos acharam por bem chamar de Carmen. Carmen seria, naquele momento, um código do grupo para a chamada de um estado de presença brincante. No processo, Carmen começava a significar toda liberdade retirada do corpo por privações impostas socialmente e, como código cênico, passou a compor todas as aulas/ensaios, o que passava a justificar o título do projeto. Aqui é interessante retomar a noção bakhtiniana de relações dialógicas, conceito central para o pensamento bakhtiniano. Para Bakhtin "as relações dialógicas são possíveis não apenas entre enunciações integrais (relativamente), mas o enfoque dialógico é possível a qualquer parte significante do enunciado [...]" (2010b, p. 210).

No projeto discursivo bakhtiniano, o texto é considerado tanto como objeto de significação como objeto de comunicação, sendo que a concepção de texto está atrelada à noção de enunciado, no qual as abordagens internas e externas da linguagem se conciliam. Se é na cadeia de textos que os sentidos são produzidos, Carmen começou, também, a produzir sentidos entre seus integrantes por se firmar na fronteira entre o individual e o coletivo. Por mais que as memórias, imagens e estados alcançados fossem, de certa forma, individuais, era na troca com o outro que ganhavam sentido e se juntavam à voz uníssona da dramaturgia coletiva.

Em outro momento do processo, foi realizada uma experiência virtual nas quais o tema recorrente remontou à volúpia e às limitações e/ou liberdades sexuais do corpo. Os alunos-atores foram convidados a entrar, no mesmo momento, em uma sala de bate-papo on-line, com nomes fictícios. Em poucos minutos, a sala, que havia iniciado somente com os integrantes do processo, já contava com quarenta participantes. Os alunos-atores foram cuidadosamente direcionados a não se identificarem e não abrirem webcams para que pudessem preservar seu anonimato na experiência proposta. $\mathrm{O}$ resultado desta experiência foi 
a criação de uma cena a partir das textualidades que se recorrentes da sala de bate-papo.

Os alunos também foram convidados a uma vivência corporal a partir da música Com Magia, tema do filme Barbie - O portal secreto. Esta referência atuou como pulverizadora de memórias dos sujeitos e por meio dela foi possível discutir a influência dos bonecos Barbie e Ken sobre as experiências corporais de homens e mulheres desde a infância. A música, como praticamente todos os temas musicais da boneca Barbie, fala de um lugar encantado no qual, com magia, tudo se torna possível. Aqui, mais uma vez, abre-se espaço para a discussão da noção bakhtiniana de relações dialógicas e sua mobilização enquanto possibilidade para se pensar as vozes que constituem os sujeitos.

A letra da música, ouvida em sala de aula e experienciada corporalmente pelos participantes do processo cênico Carmen, instiga o seu interlocutor a se lançar nas mais ousadas aventuras e ser o que quiser. O contraponto com a temática do espetáculo se dá, justamente, pelo entendimento de que somente com magia é que o sujeito consegue ser "dono" do seu próprio corpo e dar-lhe, assim, os direitos de fazer o que bem entender. A pergunta disparadora do processo criativo, "o que o corpo não pode?" tem, na letra da música, uma resposta pronta, mas utópica diante do real e do presente, o que provocou nos integrantes de Carmen uma atitude responsiva frente ao vivido que só poderia se configurar em uma construção cênica assumidamente crítica e de reação a modelos impostos na ordem discursiva vigente, que insiste em determinar o que o corpo deve ou não deve fazer.

O processo conta, ainda, com momentos nos quais os alunosatores são convidados a falar de suas memórias do/sobre/com o corpo, incluindo aí depoimentos de fatos marcantes que tem contribuído para a experimentação de suas narrativas corporais, compreendidas, neste processo, como não finalizadas, in process, vinculadas diretamente ao vivido e às relações com o outro (sujeito, espaço, tempo). Em alguns momentos do espetáculo, as teatralidades tateiam entre histórias reais e fictícias, levando o público a um desejo de desvendar/desvelar o que realmente inquieta os alunos-atores. A esfera de produção dramatúrgica de Carmen se reconhece, desse modo, na hibridização de memórias, fatos, imagens, recordações e encontros que, como projeto discursivo 
funcionam como tema uníssono, profícuo e repleto de sentidos a serem (re)explorados e (re)elaborados.

O diálogo com a teoria bakhtiniana se dá, ainda, neste trabalho, a partir do texto $O$ problema do conteúdo, do material e da forma na criação literária (PCMF), escrito por Bakhtin em 1924 e publicado no volume Questões de Literatura e de Estética - A teoria do Romance (conjunto de ensaios, escrito entre 1924 e 1941, organizado pelo autor em Moscou, e publicado somente em 1975, após sua morte; publicado no Brasil em 1988). Em PCMF, Bakhtin (2010a) faz uma discussão a respeito de Crítica da Arte e Estética Geral, apontando principalmente para a impossibilidade de separação entre poética e estética. Depois, ao desenvolver separadamente cada um dos "problemas": Conteúdo, Material e Forma, sua abordagem ganha o sentido de inter-relação entre cada uma das partes componentes de uma obra de arte.

É aí que vemos o Conteúdo como o conjunto de limites de certo domínio cultural, que está sempre nas fronteiras, implicando o jogo necessário entre o ético e o cognitivo; o Material como ato concreto, possibilitado pela palavra, pela língua viva, e que desencadeia uma importante reflexão sobre a técnica no fazer artístico; e a Forma como forma de um Conteúdo, inteiramente realizada no Material, e que deve ser compreendida tanto a partir do interior do objeto estético puro (forma arquitetônica), como a partir do estudo da técnica da forma (o todo composicional e material da obra de arte).

Para os processos de criação teatral em contextos educacionais, é fundamental a compreensão de que uma criação está sempre em uma relação de valores com outras pessoas, outros objetos, outras coisas. Pessoas, objetos e coisas que vivem juntos, o mundo da arte e o mundo da educação. A obra de arte parte de um ato cultural, noção cara aos estudos bakhtinianos, e é alicerçada pelo fato de que ele, o ato cultural, "vive por essência sobre fronteiras: nisso está sua seriedade e importância; abstraído da fronteira, ele perde terreno, torna-se vazio, pretensioso, degenera e morre" (BAKHTIN, 2010a, p. 29). Logo, há pontos de vista na criação, que estão sempre em diálogo, e são esses pontos de vistas criadores que garantem à arte seu status de obra, ou de objeto estético. 
Para o teatro, que se constitui como criação coletiva, de grupo, essa reflexão tem muito a contribuir, pois ao pensar o ato artístico como um movimento que acontece em uma atmosfera valorizante, definida reciprocamente, se assume o conflito dos processos e sua íntima ligação com os sujeitos que concretizam sua existência como fenômeno cênico. A coletividade é, então, o centro de preocupações da criação artística, na qual ganha espaço de discussão a necessidade de compreensão da liberdade de criação do artista, calcada na relação com um mundo a ser conhecido e provado.

Como o pensamento bakhtiniano anuncia de forma absolutamente coerente em todas as suas obras, o ato é sempre relativizado. Há sempre uma possível noção de verdade. Nas fronteiras entre os valores axiológicos, o enunciado concreto será sempre cheio de sentidos relativamente estáveis, pois "A obra de arte e a contemplação se relacionam com os sujeitos éticos, com os sujeitos do comportamento e com suas inter-relações sociais" (BAKHTIN, 2010a, p. 43). Dessa forma, o espaço para a interpretação da obra de arte está dado e é pela ótica das relações dialógicas que o teatro na educação precisa ser revisto, revisitado e reorganizado teórico-metodologicamente.

Mesmo que, por um momento, o teatro em contextos de educação deva possibilitar a sensação comum de uma experiência compartilhada e papéis carregados de binômios (professor-ator, professor-diretor, professor-artista, artista-pesquisador, aluno-ator, aluno-produtor, aluno-pesquisador), cada sujeito terá vivido sua própria experiência, e terá extraído dela, sentidos que, por sua vez, funcionam também como constitutivos das identidades, revisitadas, sempre, pelas frestas da alteridade. Cada sujeito, com seu olhar único, sua posição única e a partir de um momento irrepetível, vivencia e contempla a obra de arte, num jogo de sentidos que individualiza os processos de alteridade a partir da arte, fazendo com que para cada um, os sentidos sejam também únicos e, portanto, diferentes dos provocados nos demais integrantes de um processo.

É na exploração dessa perspectiva que o processo Carmen tem encontrado lugares de autoria em meio à academia, que passam sempre por construções individuais e reconstruções de grupo, para que o espetáculo se organize de forma coerente e para que a temática se 
apresente com pelo menos alguns indícios de arquitetônica uníssona, ou seja, que o emaranhado de vozes construa sentido para um todo complexo e nem sempre harmonioso.

\section{Conclusĩo}

Esse texto se ateve a provocar reflexões sobre o processo de construção dramatúrgica do espetáculo Carmen, desenvolvido com alunos da graduação em Produção Cênica da Universidade Federal do Paraná. Pensado como um processo no qual os sujeitos pudessem vivenciar experiências e a partir delas construir um trabalho cênico com base em suas memórias e trajetórias, Carmen busca por responder a questão: o que o corpo não pode?

$\mathrm{O}$ projeto se desenvolveu durante quatro semestres acadêmicos e em momento algum quis se afirmar como espetáculo pronto, ou seja, o caráter laboratorial tem sido essencial para a compreensão do inacabamento como fator intrínseco aos percursos trilhados.

Ao longo do texto, buscaram-se aproximações entre a teoria dialógica de Bakhtin e o Círculo e o processo em questão, e desses encontros foi possível depreender sentidos que abrem discussões relacionadas às noções centrais para o pensamento bakhtiniano como esfera, objeto artístico, estética, autoria e a própria concepção de texto/ discurso que ultrapassa as fronteiras da dimensão oral/escrita e tem, neste trabalho, o corpo como lugar privilegiado para o dizer/enunciar.

O processo Carmen apresenta, hoje, diferentes materialidades a partir do qual pode ser analisado, desde aquelas advindas da sua criação (experimentos cênicos realizados em sala de aula) até aquelas que apresentam os resultados das experiências dramatúrgicas (partituras corporais individuais e o espetáculo em sua versão "acabada"). Temos discutido, já, em outros trabalhos (GONÇALVES, 2014; GONÇALVES; GONÇALVES; PLUSCHKAT, 2015) a necessidade de retomada e rediscussão da noção de discurso teatral que, em diálogo com as teatralidades contemporâneas, abarca uma série de dados recheados de elementos teatrais que ultrapassam a caixa cênica (flyers, folders, matérias de jornal, protocolos verbais, visuais e ou verbovisuais, registros, memórias, teasers, documentários). 
Pensar o discurso teatral de Carmen como um processo realizado em um contexto de formação acadêmica é, desse modo, abrir horizontes para um universo de jeitos, estranhamentos, novidades e pluralidades de manuseio de pesquisa. No caso das escolhas feitas nesse texto, que se aproximam mais de um prólogo para futuros leitores do que de uma análise de resultados propriamente dita, duas questões se colocam, então, para discussão: a) Quais os limites e possibilidades da criação dramatúrgica quando esta se dá pela prática corporal do ator? Para respondê-la é necessário que firmemos o acordo de que, mais do que uma obra teatral, Carmen se constitui como um processo educativo no qual reverberam as Artes do Corpo (ANDRÉ, 2002), ou seja, há lugar para performance, dança, rituais, cantigas, e para a compreensão do corpo como arte e principalmente como efervescência dramatúrgica a ser explorada em um contexto de educação; b) Como organizar artisticamente o desejo de dizer a partir do corpo e no corpo do alunoator? Lançando a âncora, ainda, nas Artes do Corpo como propulsoras de sentido, é preciso pensar o corpo como lugar apropriado para as encenações do desejo, "porque toda a encenação é a encenação do desejo no sentido mais literal da expressão: pôr em cena o desejo ou deixar o desejo vir à cena, à boca de cena através de todas as suas metamorfoses" (ANDRÉ, 2002, p. 25). E esse desejo se traduz por palavras, que brotam do corpo dos participantes da criação cênica, que dançam nas e entre as esferas de criação poética e educacional e, ainda, na apreciação/relação dialógica de um processo artístico-educacional em seu encontro com o público.

\section{CARMEN IN DIALOGICAL PERSPECTIVE: RESTLESS REVERBERATIONS OF A DRAMATURGICAL-PERFORMATIVE CONSTRUCTION PROCESS IN THE UNIVERSITY CONTEXT}

\section{AbSTRACT:}

The aim of this paper is to reflect on the dramaturgical construction process of the theatrical spectacle Carmen, held in the context of an undergraduate course on Scenic Production of the Federal University of Paraná. The relations with the theory are established from the dialogical perspective of Bakhtin Circle. The results point to links between the educational sphere, the scenic speech and the consequent mobilization of Bakhtin's notion of dialogical relations, 
suggesting different possibilities to think about the dramaturgical construction in a project rooted in the body as enunciator and producer of meanings.

KEYworDs: Dramaturgical-performative construction, body, university, Bakhtin Circle.

CARMEN EN PERSPECTIVA DIALÓGICA: REVERBERACIONES INQUIETAS DE UN PROCESO DE CONSTRUCCIÓN DRAMATÚRGICO-PERFORMATIVA EN EL ÁMBITO UNIVERSITARIO

\section{RESUMEN:}

El objetivo de este trabajo es reflexionar sobre el proceso de construcción dramatúrgica del espectáculo Carmen, realizado en el contexto de educación universitaria en Producción Escénica, Universidad Federal de Paraná. Las relaciones con la teoría se establecen desde la perspectiva dialógica que tiene en la producción intelectual de Bajtín y el Círculo su principal base teórica. Los resultados permiten entrever los vínculos entre el ámbito educativo, el discurso escénico y la consiguiente movilización de la noción bajtiniana de relaciones dialógicas, lo que sugiere diferentes posibilidades para pensar la construcción dramatúrgica en una concepción arraigada en el cuerpo como enunciador y productor de significados.

Palabras-clave: Construcción dramatúrgico-performativa, cuerpo, universidad, Bajtín y el Círculo.

\section{NotA}

1 Carmen, em nenhum momento, se limitou a um nome de apresentação. Entre os mais recorrentes estão: performance, peça teatral, processo cênico, espetáculo, acontecimento performático, experimento cênico e processo experimental. $\mathrm{O}$ grupo não faz questão de se firmar em uma nomenclatura que possa dar conta do significado de Carmen. Nesse texto também não há restrições de nomenclatura para Carmen. 


\section{REFERÊNCIAS}

AMORIM, Marília. O pesquisador e seu outro: Bakhtin nas Ciências Humanas. São Paulo: Musa Editora, 2004.

ANDRÉ, João Maria. As Artes do Corpo e o Corpo como Arte. Philosophica, Revista do Departamento de Filosofia da Faculdade de Letras da Universidade de Lisboa. Lisboa, v. 19, n. 20, p. 7-26, 2002.

AZEVEDO, Sônia Machado de. O papel do corpo no corpo do ator. São Paulo: Perspectiva, 2012.

BAKHTIN, Mikhail; VOLOSHINOV, Valentin Nikolaevich. Marxismo e filosofia da linguagem: problemas fundamentais do método sociológico na ciência da linguagem. Tradução para a Língua Portuguesa: Michel Sahud e Yara Frateschi Vieira. São Paulo: Hucitec, 2010.

BAKHTIN, Mikhail. Estética da Criação Verbal. 4. ed. São Paulo: Ed Martins Fontes, 2003.

. [1924]. O problema do Conteúdo, do Material e da Forma na Criação Literária. In: BAKHTIN, Mikhail. Questões de Literatura e de Estética: A Teoria do Romance. Tradução (do Russo): Aurora Bernardini, José Pereira Júnior, Augusto Góes Júnior, Helena Nazário e Homero Freitas de Andrade. 6. ed. São Paulo: Hucitec Editora, 2010a. p. 13-70.

. O discurso no romance. In: BAKHTIN, Mikhail. Questões de literatura e de estética (A Teoria do Romance). 6. ed. Trad. Aurora Bernardini, José Pereira Júnior, Augusto Góes Júnior, Helena Nazário \& Homero F. de Andrade. São Paulo: Ed. Hucitec, 2010b.

BRAIT, Beth. Bakhtin e a natureza constitutivamente dialógica da linguagem. In: BRAIT, Beth. Bakhtin: dialogismo e construção do sentido. 2. ed. revisada. Campinas: Editora da Unicamp, 2005.

- Construção coletiva da perspectiva dialógica: história e alcance teórico-metodológico. In: FIGARO, Roseli. (Org.). Comunicação e Análise do Discurso. São Paulo: Contexto, 2012.

GONÇALVES, Jean Carlos. Circo negro: o discurso teatral em perspectiva dialógica. In: BRAIT, Beth; MAGALHÃES, Anderson Salvaterra. (Org.). Dialogismo: teoria e(m) prática. São Paulo: Terracota, 2014.

GONÇALVES, Jean Carlos; GONÇALVES, Michelle Bocchi; PLUSCHKAT, Patricia. Dubsmash em perspectiva dialógica: do desejo de dizer ao desejo de performance. Revista Línguas e Letras. Cascavel, v. 16, n. 34. Cascavel: 
UNIOESTE, 2015. Disponível em: <http://e-revista.unioeste.br/index.php/ linguaseletras/issue/view/772>. Acesso em: 10 maio 2016.

GRILLO, Sheila. Esfera e Campo. In: BRAIT, Brait. Bakhtin, Outros Conceitos-Chave. São Paulo: Contexto, 2008.

. A obra em contexto: tradução, história e autoria. In: MEDVIÉDEV, Pável Nikoláievitch. O método formal nos estudos literários: introdução crítica a uma poética sociológica. São Paulo: Contexto, 2012.

KRAMER, Sônia. Linguagem e tradução: um diálogo com Walter Benjamin e Mikhail Bakhtin. In: FARACO, Carlos et al. Diálogos com Bakhtin. Curitiba: Editora UFPR, 2007.

FARACO, Carlos. O dialogismo como chave de uma antropologia filosófica. In: FARACO, Carlos et al. Diálogos com Bakhtin. Curitiba: Editora UFPR, 2007.

LOPES, Luis Paulo Moita. Discursos de identidade em sala de aula de L1: a construção da diferença. In: SIGNORINI, Inês. Linguagem e identidade: elementos para uma discussão no campo aplicado. Campinas: Mercado de Letras/FAPESP, 1998.

PICON-VALLIN, Beatrice. A cena em ensaios. São Paulo: Perspectiva, 2008. SCHINO, Mirella. Alquimistas do palco. São Paulo: Perspectiva, 2012.

Submetido em 28 de abril de 2016.

Aceito em 1 de junho de 2016.

Publicado em 29 de setembro de 2016 
